\title{
Emission permits and the dynamics of clean and dirty firms in an evolutionary competition model
}

\author{
Angelo Antocia ${ }^{\mathrm{a}}$ Simone Borghesib,c,*, Gianluca Iannuccid ${ }^{\mathrm{d}}$, Paolo Russu $^{\mathrm{a}}$

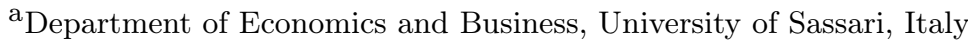 \\ ${ }^{\mathrm{b}}$ FSR Climate, European University Institute, Florence, Italy \\ ${ }^{\mathrm{c}}$ Department of Political and International Sciences, University of Siena, Italy \\ ${ }^{\mathrm{d}}$ Department of Economics and Management, University of Florence, Italy
}

Accepted for publication in Metroeconomica

\begin{abstract}
Emission Trading Systems (ETSs) are today regarded as the pillar of market-based environmental policies in many countries. This paper studies the impact of an ETS on the dynamics of the market made up of two types of firms: clean and dirty. Using an evolutionary context, we study how the share of clean firms evolves at different parameter values, such as increasing values of the permits' price floor, and show that an ETS can have positive effects on the diffusion of the clean technology. However, numerical simulations show that under specific parameter values the opposite result may emerge with clean firms leaving the market.
\end{abstract}

Keywords: Emission trading system, Replicator dynamics, (Non) Polluting technologies. JEL Classification: C73, D24, O13, O33, Q55.

${ }^{*}$ Corresponding author. Florence School of Regulation - EUI, Via Boccaccio 121, 50133 Firenze. / Department of Political and International Sciences, University of Siena, Via Mattioli 10, 53100 Siena.

E-mails: antoci@uniss.it (A. Antoci), simone.borghesi@eui.eu / simone.borghesi@unisi.it (S. Borghesi), gianluca.iannucci@unifi.it (G. Iannucci), russu@uniss.it (P. Russu). 


\section{Introduction}

In the last few years the economic literature has devoted increasing attention to the functioning and effects of Emission Trading Systems (ETSs). An ETS is a cap-and-trade system that has the goal of reducing firms' emissions by setting a price for emission allowances. In an ETS regulated firms are initially allocated a given number of emission allowances, either for free on the basis of historical emissions (grandfathering) or via an auctioning mechanism. Participants can subsequently exchange emissions allowances on the secondary market. Among existing ETSs, the largest and most famous scheme is certainly the European Emission Trading System (EU ETS) that was originally established in 2005. The EU ETS has now several followers in other world areas, such as California, the Eastern cost of the United States (the so-called Regional Greenhouse Gas Initiative), Quebec and China, to mention just the most important ones (Borghesi et al., 2016; International Carbon Action Partnership, 2017; World Bank, Ecofys and Vivid Economics, 2017). Today there are twenty-one ETSs operating in the world, covering 15 per cent of global emissions (International Carbon Action Partnership, 2018). Existing ETSs show remarkable differences but also striking similarities (Borghesi and Montini, 2016). One common feature that all ETSs share, for instance, is the progressive shift from grandfathering to auctioning. This shift has raised in all ETSs a debate on whether to set a minimum auction price (i.e. a price floor) to prevent prices from falling too much when permits' demand declines. Differently from the EU ETS, which has no price lower bound, most other ETSs have introduced a price floor, though in different ways (cf. Wood and Jotzo, 2011) and at different price levels. ${ }^{1}$

The aim of this paper is to analyse, through an evolutionary game theoretical model, ${ }^{2}$ the effect of an ETS on the dynamics of clean and dirty firms that are subject to an emission permits scheme. Indeed, if the permit's price increases companies could consider convenient to invest in

\footnotetext{
${ }^{1}$ Price floor levels differ remarkably across ETSs, ranging from around 2.3 US dollars per ton of carbon dioxide (tCO2) in the Regional Greenhouse Gas Initiative and $€ 2.7 / \mathrm{tCO} 2$ in Beijing to around 10 US dollars (and rising at 5 per cent every year) in California. Also within the EU ETS, some national governments have supported the application of a lower bound in the price level. In particular, the UK has unilaterally decided to adopt a carbon price floor equal to $£ 9 /$ tCO2 for its electricity sector in 2013 , which initially doubled to $£ 18 /$ tCO2. The Dutch government has committed to do the same, while France has called for an EU-wide price floor (Newbery et al., 2018).

${ }^{2}$ Differently from random matching models in which agents interact randomly pairwise, we propose here a "population game" in which all agents indirectly interact with each other through the market. This can capture, for instance, one important feature of the EU ETS, namely, the fact that the activity of one agent subject to the EU ETS may affect that of any other agent regulated by the system through changes in the permits' price, no matter the country the agents belong to.
} 
a new more environmental-friendly technology rather than keep on buying further permits, thus contributing to the technological shift that is needed to reduce polluting emissions.

Most of the studies on this topic have performed empirical estimations using either surveys of managerial interviews (see e.g., Hoffmann, 2007; Aghion et al., 2009; Rogge et al., 2011) or econometric modelling (see, e.g., Ellerman and Buchner, 2008; Borghesi et al., 2015; Calel and Dechezlepretre, 2016). However, the empirical studies conducted so far generally find mixed evidence so that there is no consensus on the effects of the ETS on low-carbon innovations and on the diffusion of clean technologies (Martin et al., 2016). ${ }^{3}$

While the empirical literature on this subject is quite extensive, the theoretical literature is relatively scarce. Indeed, most of the theoretical works on ETSs deal with the optimal number of allowances to be allocated on the market and on the related carbon prices (see, e.g., Grüll and Taschini, 2011; Fell et al., 2012; Kollenberg and Taschini, 2016; Perino and Willner, 2016). Several other studies (see, among others, Malueg, 1989; Milliman and Prince, 1989; Jung et al., 1996; Unold and Requate, 2001; Requate, 2005) have focused on aggregate cost-savings deriving from the adoption of new technologies in cap-and-trade systems. Only few theoretical works deal with the firms' behavior looking at their ecoinnovation in response to the implementation of an ETS (Moreno-Bromberg and Taschini, 2011; Antoci et al., 2014). In particular, Moreno-Bromberg and Taschini (2011) examine the allowance prices formation process and its impact on the incentive to adopt new technology under a transferable permits system in a non-cooperative game theoretical model with strategic trading behaviors. The authors propose a self-financing policy instrument (named European-Cash-4-Permits) that can create dynamic incentives to invest in low pollutionemitting technologies and show that this new instrument may generate a floating price floor in the permit system. Antoci et al. (2014) also look at how a system of tradable permits may affect the diffusion of environment-preserving technological innovations in the presence of sanctions to non-compliant firms. For this purpose, they set-up a random matching model in which firms act strategically and decide whether to exchange permits based on the expected sanction suffered by non-compliant firms.

\footnotetext{
${ }^{3}$ Most empirical studies find that the EU ETS has had a limited impact on low-carbon innovation promoting mainly small-scale investments (Marcantonini et al., 2017). In this paper, we will not discuss ETS-related innovation activities as we will assume clean and dirty technologies to be exogenously given, but we will rather look at the relative diffusion of such technologies in a population of firms subject to the ETS.
} 
The present paper differs from previous theoretical studies in several respects: (i) it studies the dynamic regimes characterized by the existence of clean and/or dirty firms; (ii) it shows the possible existence of a stationary state with dirty firms only; (iii) it examines the impact of a price floor on the dynamics of clean and dirty firms assuming competitive markets. To investigate this issue the present paper is structured as follows. Section 2 presents the model, Section 3 deals with output choices, replicator equations, and dynamic regimes. Numerical simulations are performed in Section 4 and Section 5 concludes.

\section{The model}

Let us consider the dynamics of a $N$-size population of firms that produce a unique homogeneous good using different (polluting vs non-polluting) technologies. ${ }^{4}$ Each firm has to choose between two possible strategies: using a polluting ("dirty") technology that requires emission permits to carry on the production activity or using a non-polluting ("clean") technology that requires no permits to operate ${ }^{5}$. Denoting clean and dirty firms with subscripts $i=c, d$ respectively, we assume their profit functions to be as follows:

$$
\begin{gathered}
\pi_{c}=p \cdot q_{c}-C_{c}^{f}-\frac{C_{c}^{v}}{2} \cdot q_{c}^{2} \\
\pi_{d}=p \cdot q_{d}-C_{d}^{f}-\frac{C_{d}^{v}}{2} \cdot q_{d}^{2}-p_{t} \cdot q_{d}
\end{gathered}
$$

where $p$ is the unit price of the good produced by the firms, $q_{i}$ represent the quantities produced, $C_{i}^{f}>0$ and $C_{i}^{v}>0$ are the fixed and variable costs, respectively, $p_{t}$ indicates the unit price of tradable permits. Moreover, we assume that supply of available technologies is infinitely elastic and the number of firms of each type is not constrained by the available production factors. ${ }^{6}$

To consider all possible cases, we allow the (fixed and variable) costs of clean firms to be higher than, equal to or lower than those of dirty firms, namely, $C_{c}^{j} \leqq C_{d}^{j}$ (where $j=f, v$ ).

\footnotetext{
${ }^{4}$ Energy provides a suitable example of a homogeneous good that can be produced using either clean or dirty technologies, e.g. renewable energy sources or fossil fuels. Indeed, the "Power and heat generation" industry represents the major sector subject to the EU ETS. In particular, the electric sector alone receives more than 40 percent of the total European Union Allowances allocated annually on the market (Martin et al., 2016).

${ }^{5}$ For the sake of simplicity, we assume that firms cannot use both technologies simultaneously but adopt exclusively one of them at each point in time.

${ }^{6}$ We do not model here the production of the available technologies and the inputs market as this goes beyond the focus of the present work.
} 
Indeed, on the one hand adopting the clean technology can be more expensive than using the old one, but on the other hand labor productivity can be higher (and hence unit labor costs lower) in firms using the clean technology (see, e.g., Chang et al., 2016; Graff Zivin and Neidell, 2012; Graff Zivin and Neidell, 2013). ${ }^{7}$

Denoting with $x \in[0,1]$ and $1-x$ the shares of clean and dirty firms, respectively, the inverse demand of the good produced by the firms is given by the following linear function:

$$
p=\bar{p}-\alpha \cdot\left[q_{c} \cdot x \cdot N+q_{d} \cdot(1-x) \cdot N\right]
$$

where $\bar{p}>0$ is the reservation price and $\alpha>0$ measures the derivative of the output price with respect to aggregate output (namely, the slope of the demand function). The value $\left[q_{c} \cdot x \cdot N+q_{d} \cdot(1-x) \cdot N\right]$ represents the aggregate output produced by the market (composed of both types of firms). Therefore, an increase of $\alpha$ and/or of $q_{i}$ results into a decrease of the output price.

Conversely, the permits demand is assumed to be proportional to the total output $q_{d} \cdot(1-x) \cdot N$ produced by dirty firms and the unitary price $p_{t}$ of the permits is determined by the equation:

$$
p_{t}=\overline{p_{t}}+\beta \cdot q_{d} \cdot(1-x) \cdot N
$$

where $\overline{p_{t}} \geq 0$ is the exogenous price floor and $\beta>0$ measures the derivative of the permits price with respect to dirty firms' output. We assume that dirty firms buy permits only for production purposes. We exclude the existence of a secondary market and of permits demand for precautionary or speculative reasons. Finally, dirty firms can buy any amount of emission permits at the prevailing price. ${ }^{8}$

Each firm maximizes its own profit $\pi_{i}(x)$ taking $p$ and $p_{t}$ as exogenously given. In other words, we assume perfect competition both in the output and in the permits market. The time

\footnotetext{
${ }^{7}$ Notice that if both fixed and variable costs of clean firms are lower than those of dirty firms, then the former will certainly enjoy higher profits than the latter (that have also to purchase the pollution permits). In this case, therefore, the strategy "clean" strictly dominates the strategy "dirty" and the dynamics of the model becomes trivial (all firms choose to be clean).

${ }^{8}$ We implicitly assume the supply of the emission permits to be exogenously given by the regulator and price adjustments to be determined by changes in the demand side. In reality the regulator can modify the supply of permits adapting it to changes in environmental targets and economic circumstances. However, we assume here that the regulator is either unwilling or unable to modify the supply of permits (say, for political reasons) to counterbalance changes in the demand side.
} 
evolution of $x$ is assumed to be given by the well-know replicator equation (see, among others, Hofbauer and Sigmund, 1988; Weibull, 1995):

$$
\dot{x}=x \cdot(1-x) \cdot\left[\pi_{c}(x)-\pi_{d}(x)\right]
$$

where $\dot{x}=d x / d t$ is the time derivative of the share $x$. Dynamics (4) assumes that if adopting a clean technology is more profitable than using a dirty one, namely, $\pi_{c}(x)>\pi_{d}(x)$, then the share of clean firms increases; the opposite occurs if $\pi_{c}(x)<\pi_{d}(x)$. Finally, if $\pi_{c}(x)=\pi_{d}(x)$, then the share of clean firms does not change over time.

\section{Dynamics}

In this section we present the quantities chosen by firms, the replicator equation, and the dynamic regimes that emerge from the analysis of the model.

\subsection{Output choices}

Given the value of variable $x$, the quantities $q_{c}$ and $q_{d}$ are chosen according to the first order conditions:

$$
\begin{gathered}
\frac{\partial \pi_{c}}{\partial q_{c}}=p-C_{c}^{v} q_{c} \leq 0, \quad \frac{\partial \pi_{c}}{\partial q_{c}} \cdot q_{c}=0 \\
\frac{\partial \pi_{d}}{\partial q_{d}}=p-C_{d}^{v} \cdot q_{d}-p_{t} \leq 0, \quad \frac{\partial \pi_{d}}{\partial q_{d}} \cdot q_{d}=0
\end{gathered}
$$

From the condition (5), it follows that clean firms always choose $q_{c}>0$ for $p>0$, and therefore the value of $q_{c}$ is determined by the condition:

$$
\frac{\partial \pi_{c}}{\partial q_{c}}=p-C_{c}^{v} \cdot q_{c}=0
$$

Differently from (5), the condition (6) could be satisfied for $q_{d}=0$ and $\frac{\partial \pi_{d}}{\partial q_{d}}<0$. Therefore, dirty firms, which buy emission permits, could choose to produce a zero output, given $x$. Such an event can occur only if $\overline{p_{t}}>0$ and, therefore, $p_{t}>0$ also for $q_{d}=0$. Consider first the case in 
which (6) is satisfied for $q_{d}>0$, and consequently the following condition holds:

$$
\frac{\partial \pi_{d}}{\partial q_{d}}=p-C_{d}^{v} \cdot q_{d}-p_{t}=0
$$

From (7) and (8) it derives:

$$
p-C_{c}^{v} \cdot q_{c}=p-C_{d}^{v} \cdot q_{d}-p_{t}
$$

and then:

$$
q_{c}=\frac{\overline{p_{t}}+\left[\beta \cdot(1-x) \cdot N+C_{d}^{v}\right] \cdot q_{d}}{C_{c}^{v}}
$$

Substituting equations (2)-(3)-(10) in (8), we obtain:

$$
\bar{p}-\left(1+\frac{\alpha \cdot x \cdot N}{C_{c}^{v}}\right) \cdot \overline{p_{t}}=\left(\frac{\alpha \cdot\left[\beta \cdot(1-x) \cdot N+C_{d}^{v}\right] \cdot x \cdot N}{C_{c}^{v}}+(\alpha+\beta) \cdot(1-x) \cdot N+C_{d}^{v}\right) \cdot q_{d}
$$

Equation (11) determines the value of $q_{d}$ chosen by dirty firms. Setting $q_{d}=0$, we get:

$$
x=\widetilde{x}=\frac{\left(\bar{p}-\overline{p_{t}}\right) \cdot C_{c}^{v}}{\alpha \cdot \overline{p_{t}} \cdot N}
$$

The threshold value $\widetilde{x}$ (represented as a vertical line in Fig. 1(a) below) separates the interval $[0, \widetilde{x})$ where $q_{d}>0$ from the interval $(\widetilde{x}, 1]$ where $q_{d}=0$. Moreover, $\widetilde{x} \in(0,1)$ if and only if:

$$
\overline{p_{t}}<\bar{p}<\left(\frac{\alpha \cdot N}{C_{c}^{v}}+1\right) \cdot \overline{p_{t}}
$$

The following propositions show the equilibrium output values for $x<\widetilde{x}$ and for $x \geq \widetilde{x}$ (see (12)).

Proposition 1 In the interval $[0, \widetilde{x})$, that is when $q_{d}>0$, the equilibrium value of $q_{d}$ is given by the solution of equation (11):

$$
q_{d}^{*}=\frac{\bar{p}-\left(1+\frac{\alpha \cdot x \cdot N}{C_{c}^{v}}\right) \cdot \overline{p_{t}}}{\left(\frac{\alpha \cdot\left[\beta \cdot(1-x) \cdot N+C_{d}^{v}\right] \cdot x \cdot N}{C_{c}^{v}}+(\alpha+\beta) \cdot(1-x) \cdot N+C_{d}^{v}\right)}
$$


and the equilibrium value of $q_{c}$ is given by (10):

$$
q_{c}^{*}=\frac{\overline{p_{t}}+\left[\beta \cdot(1-x) \cdot N+C_{d}^{v}\right] \cdot q_{d}^{*}}{C_{c}^{v}}
$$

Proposition 2 In the interval $[\widetilde{x}, 1]$, where $q_{d}=0$, the equilibrium value of $q_{c}$ is given by condition (5):

$$
\widehat{q}_{c}=\frac{\bar{p}}{\alpha \cdot x \cdot N-C_{c}^{v}}
$$

\subsection{Replicator equation}

Taking into account that $p=C_{c}^{v} \cdot q_{c}\left(\right.$ from (5)) and that $p=C_{d}^{v} \cdot q_{d}+p_{t}$ (from (6)), in the interval $[0, \widetilde{x})$, where $q_{d}>0$, the replicator equation becomes:

$$
\dot{x}=x \cdot(1-x) \cdot\left[\frac{C_{c}^{v}}{2} \cdot\left(q_{c}^{*}\right)^{2}-\frac{C_{d}^{v}}{2} \cdot\left(q_{d}^{*}\right)^{2}-C_{c}^{f}+C_{d}^{f}\right]
$$

while, in the interval $[\widetilde{x}, 1]$, where $q_{d}=0$, the replicator equation becomes:

$$
\dot{x}=x \cdot(1-x) \cdot\left[\frac{C_{c}^{v}}{2} \cdot\left(\widehat{q}_{c}\right)^{2}-C_{c}^{f}+C_{d}^{f}\right]
$$

\subsection{Regimes}

Numerical simulations show that under dynamics (4) three regimes in the interval $[0,1]$ may be observed:

i) the case in which the stationary state $x=1$ is globally attractive. This occurs when the graph of $\pi_{c}(x)$ lies always above the graph of $\pi_{d}(x)$ (i.e. $\left.\pi_{c}(x)>\pi_{d}(x) \forall x \in[0,1]\right)$ so that the market is eventually composed of only clean firms (see Fig. 1(a) in case of dynamics with $q_{d} \geq 0$, and Fig. 1(b) in case of dynamics with $q_{d}>0$ );

ii) the case in which there exists an inner stationary state $x^{*} \in(0,1)$. This occurs when the graph of $\pi_{c}(x)$ crosses the graph of $\pi_{d}(x)$ at $0<x=x^{*}<1$ (i.e. $\left.\pi_{c}(x *)=\pi_{d}(x *)\right)$ so that both types of firms coexist at the equilibrium (see Fig. 1(c)); 
iii) the case in which the stationary state $x=0$ is globally attractive. This occurs when the graph of $\pi_{c}(x)$ lies always below the graph of $\pi_{d}(x)$ (i.e. $\pi_{c}(x)<\pi_{d}(x) \forall x \in[0,1]$ ) so that the market is eventually composed of only dirty firms (see Fig. 1(d)). ${ }^{9}$

It is not possible to compute analytically the number of inner states that may be observed. However, from numerical simulations, it emerges that at most one internal state $\left(x=x^{*}\right)$ may exist and it is always attractive.

\section{Simulations}

In the present section we perform numerical simulations to analyse the evolution of the share $x$ of clean firms and of their market share $\left(M S_{c}\right)$ that occurs when varying some key parameter values, namely, the permits' price floor $\bar{p}_{t}$, the reactivity of the permits' price to changes in the aggregate output of dirty firms $\beta$, and the variable costs ratio $C_{d}^{v} / C_{c}^{v}$. We define $M S_{c}$ as:

$$
M S_{c}=\frac{q_{c}^{*} \cdot x \cdot N}{q_{c}^{*} \cdot x \cdot N+q_{d}^{*} \cdot(1-x) \cdot N}
$$

The parameters underlying the simulations are the same as in Fig. 1(c), namely, the case in which both types of firms coexist.

Fig. 2(a) shows how the share of clean firms and their market share grow at increasing values of the permits' price floor $\overline{p_{t}}$. The growing trends emerging in the figure confirm our a priori expectations. Indeed, an increase in $\overline{p_{t}}$ raises the permits' price level, which reduces -ceteris paribus- the dirty firms' profits inducing a lower (higher) share of firms to choose the "dirty" ("clean") strategy. A higher permits' price floor, moreover, reduces also the output produced by dirty firms (see equation (14)). This, together with the lower share of dirty firms, reduces their market share, thus increasing its complement to one (i.e. the market share of clean firms). As the figure shows, clean firms do not need a permits' price floor to "conquest" a good share of the

\footnotetext{
${ }^{9}$ The parameters underlying Fig. 1 have been chosen so as to illustrate the various dynamic regimes that can emerge from the model. The regimes shown in the diagram hold also with different sets of parameter values, therefore the figure can be considered as representative of other parametric scenarios. Notice that in the present case we assumed the fixed costs of the clean technology to be twice as much as those of the dirty technology. This captures the possible existence of large fixed cost differentials between clean and old technologies that is often argued to hinder the transition towards cleaner production processes. In Fig. 1 the variable costs of clean technologies are instead allowed to range from much lower (one tenth) to much (fifteen times) higher than the variable costs of dirty technologies, to account for a wide range of cost differentials across different technologies.
} 


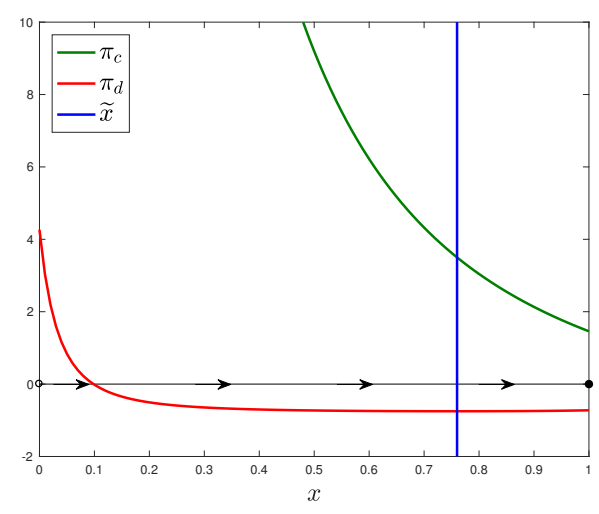

(a) Only clean firms remain on the market; $q_{d}>0$ to the left of the vertical line, $q_{d}=0$ to its right; $C_{c}^{v}=0.1$.

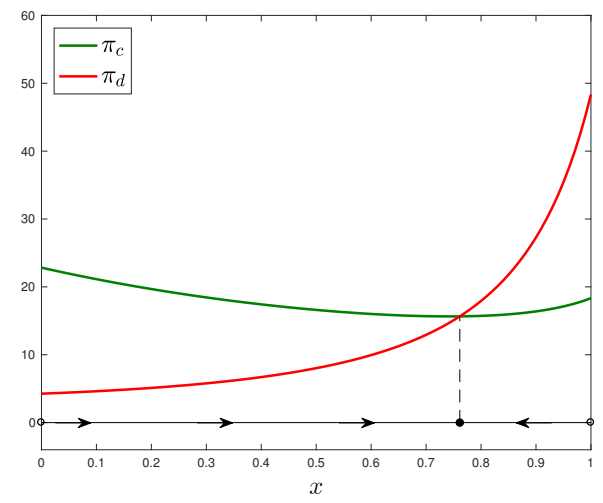

(c) Coexistence of clean and dirty firms at the equi- (d) librium; $C_{c}^{v}=3$.

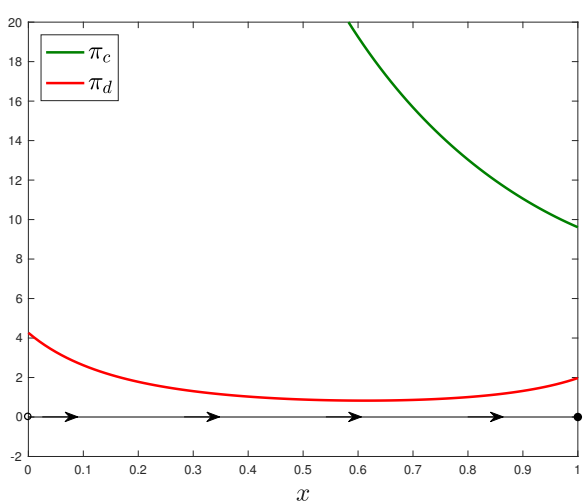

(b) Only clean firms remain on the market; $C_{c}^{v}=0.5$.

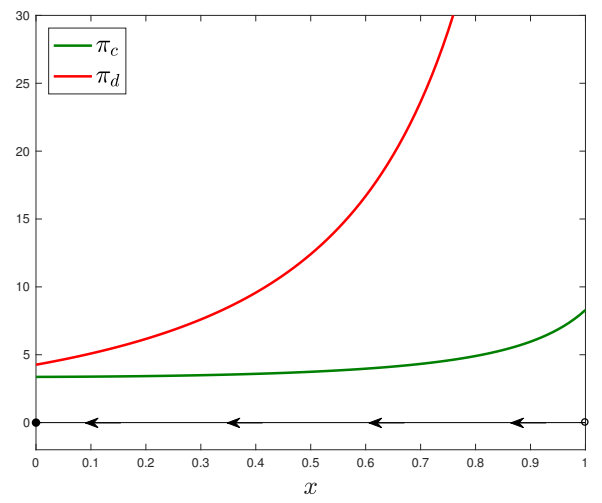

(d) Only dirty firms remain on the market; $C_{c}^{v}=15$.

Fig. 1. Dynamic regimes. Parameter values: $C_{c}^{f}=1.5, C_{d}^{f}=0.75, C_{d}^{v}=1, \bar{p}=20, \overline{p_{t}}=1, \alpha=0.5$, $\beta=0.5, N=5$. Legend: • sinks, 。 sources.

market (their market share being above 55 per cent even when $\overline{p_{t}}=0$ ). However, the introduction of a permits' price floor can rapidly increase both the share of clean firms and their market share, eventually inducing dirty firms to disappear from the market. Given our initial parameter values, in the present context this occurs when $\overline{p_{t}}$ gets slightly above 4.5 . This suggests that the government can affect the composition of the ETS-regulated market and eventually induce all firms to move to a clean technology by properly introducing a permits' price floor. ${ }^{10}$

\footnotetext{
${ }^{10}$ The price floor could be treated as an endogenous -rather than exogenous- policy variable which is set by the regulator according to some policy rule so as to increase the share of clean firms. We thank an anonymous referee for pointing out this possible extension of the present work that is left for future research.
} 
Fig. 2(b) shows how clean firms and their market share change at different values of $\beta .{ }^{11}$ As one might expect, an increase in $\beta$ is accompanied by higher values of both $x$ and $M S_{c}$. In fact, an increase in $\beta$ raises -ceteris paribus- the permits' price. This reduces the profits of dirty firms, increasing the share of clean firms in the market. Furthermore, higher values of $\beta$ tend to decrease (increase) the output produced by dirty (clean) firms (see equations (14) and (15)). Notice that if $\beta$ is sufficiently low (close to 0 in Fig. 2(b)), no firm adopts the clean technology at the equilibrium $(x=0)$. As a matter of fact, in this case all firms will prefer to use the dirty technology and ask for permits as this will not increase much the permits' price (the price reactivity being low). Also observe that both the share and the market share of clean firms grow at decreasing rates as $\beta$ grows. Indeed, a rise in $\beta$ initially causes a rapid increase in both variables. However, this growth slows down (and the curve flattens out) as $x$ approaches 1 since the number of dirty firms gets lower and lower, therefore at higher values of $\beta$ only few firms can still change their strategy and become clean. The growth of $x$, moreover, gets progressively slower also because higher $\beta$ values tend to reduce the overall output by dirty firms, as pointed out above. This lowers permits' price, ceteris paribus, thus decreasing the incentive for dirty firms to change their technology.

Finally, Fig. 2(c) shows the evolution of $x$ and $M S_{c}$ at increasing values of the variable costs ratio. The latter can be interpreted as an increase in the relative costs of the dirty technology compared to the clean one. As emerges from the figure, in this case $x$ and $M S_{c}$ show different trends: $\mathrm{U}$-shaped for $x$, monotonically increasing for $M S_{c}$. This suggests that an improvement in the new technology compared to the old one may initially have adverse effects on the evolution of the clean firms. In fact, a reduction in the costs of the non-polluting technology tends to increase the profits of clean firms and, consequently, to decrease the share of dirty firms. However, this tends to decrease -ceteris paribus- the aggregate demand of permits and thus also the permits price. This mechanism increases (decreases), in the early stages, the share of dirty

\footnotetext{
${ }^{11}$ Recall that $\beta$ measures how permits' price react to changes in aggregate permits' demand (that are in a 1:1 relatinship with the overall output of dirty firms). Policy-makers can affect this parameter through appropriate regulatory measures. This is the case, for instance, of the Market Stability Reserve (MSR) in the EU ETS, which has been conceived "to improve the system's resilience to major shocks". This measure, that transfers back-loaded and unallocated allowances to a reserve (and eventually cancels them in case of prolonged imbalances), is likely to affect how much permits' prices react to changes in aggregate demand since the supply of auctioned permits adapts de facto to changes in the permits' demand. See European Commission (2015), Hepburn et al. (2016) and the literature cited therein, for an in-depth description of how the MSR works and its implications.
} 


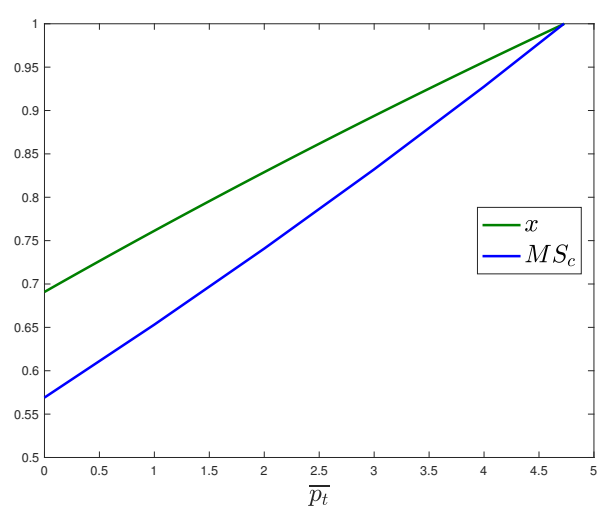

(a) Permits' price floor.

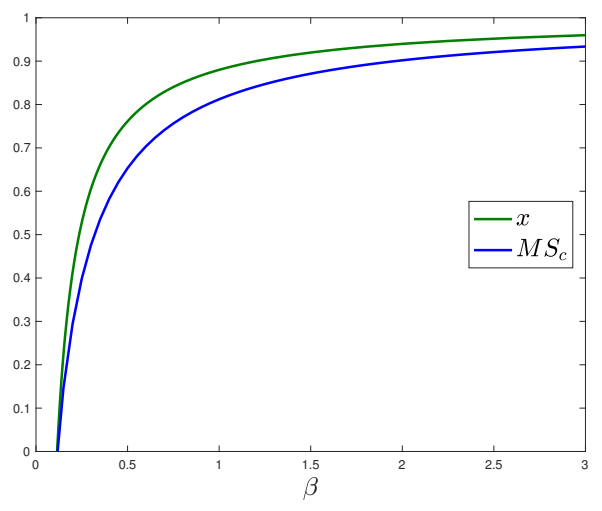

(b) Reactivity of permits' price to dirty firms' output

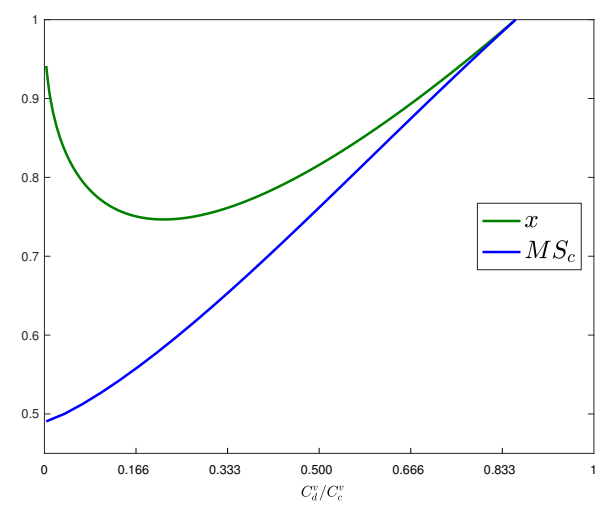

(c) Variable costs ratio.

Fig. 2. Evolution of the share of clean firms $x$ and their market share $M S_{c}$ at increasing values of $\overline{p_{t}}, \beta, C_{d}^{v} / C_{c}^{v}$.

(clean) firms themselves. However, if the costs ratio keeps increasing (so that the new technology becomes increasingly more convenient) the incentive to adopt the clean technology prevails over the benefits deriving to dirty firms from lower permits' price so that $x$ will eventually rise, which may explain the U-shaped curve that can be observed in the diagram. This possible outcome has interesting policy implications. In fact, if the policy-maker increases by a limited amount the variable costs ratio (by taxing a dirty technology or subsidising a clean one), this may have unexpected effects, reducing the share of clean firms but increasing their portion of the market. 


\section{Conclusions}

Emission Trading Schemes are one of the most widely used policy instruments to control emission levels and reduce pollution. However, only few theoretical models have investigated the impact of ETS on the diffusion of a non polluting technology in a behavioral context. To fill this gap in the literature, this paper proposes a simple dynamic evolutionary model that can describe a competitive market of tradable permits.

The theoretical framework proposed here is similar to a biological competition model (in which different species compete for a common resource). In the present case, in fact, all firms are in competition among themselves since the supply of each firm (no matter whether clean or dirty) tends to lower the price of the homogeneous good. Moreover, a decrease in $x$ (the share of clean firms), increases the permits' price $p_{t}$ thus damaging the existing dirty firms (i.e. it makes strategy dirty less convenient).

From the analysis of the model it emerges that three dynamic regimes may be observed: 1) an economy with only clean firms, 2) an economy with only dirty firms, 3) coexistence between firms. In the first case, the ETS market eventually disappears (there are no more dirty firms buying permits in the end) but its functioning contributes to achieve what we can call a complete decarbonization of the economy. In the second case, the ETS remains very active (as all firms need permits to pollute) but its presence fails to achieve the transition towards a clean economic system. In the third (and most realistic) case, clean and dirty firms coexist in the market and none of the two kinds of firms goes extinct. Moreover, numerical simulations show that by increasing the permits' price floor the share of clean firms progressively increases until it eventually gets to 1 . This result seems particularly important since it suggests that the regulator can favor the diffusion of a clean technology through a sufficiently high price floor. Numerical simulations also show the possible existence of non-linear effects in the diffusion of new technologies, so that the share of clean firms first paradoxically decreases before start increasing as the new technology gets relatively more convenient (i.e. as the variable costs ratio rises).

The results presented in this paper should be conceived as a first and preliminary step in a new research direction, namely, the investigation of the ETS effects on the diffusion of a clean technology using an evolutionary game theoretical framework that can capture the existence 
of strategic and imitative behaviors. More precisely, in our model firms "imitate" the others adopting the strategy that turns out to be the most remunerative one in the population, and behave "myopically" in the sense that they do not consider the future consequences of their choice (i.e. they are not forward-looking). Despite its analytical simplicity, however, the model can provide some relevant policy indications, particularly on the appropriate level of the price floor. The presence of lower bounds in the price level has recently proved to be very important in preventing price from collapsing in several ETSs worldwide (e.g. in California, in the Regional Greenhouse Gas Initiative that encompasses nine Eastern States of the USA, in the pilot project of Guangdong in China etc...), especially during the recent economic crisis that drastically lowered the permits' demand in several ETSs. By describing the trajectories that emerge from different price floors, the model can give policy makers important indications on how to set minimum auction prices and operate fine tuning policies that may drive a progressive shift from dirty to clean technologies in the future.

\section{Acknowledgements}

Gianluca Iannucci gratefully acknowledges support of his research activities from Fondazione Cassa di Risparmio di Firenze, under research fellowship Giovani Ricercatori Protagonisti 2016.

\section{References}

Aghion, P., Veugelers, R., Serre, C., 2009. Cold start for the green innovation machine. Bruegel Policy Contribution 2009/12.

Antoci, A., Borghesi, S., Sodini, M., 2014. Emission Trading Systems and technological innovation: a random matching model. The Oxford Handbook of the Macroeconomics of Global Warming, in Semmler W. and Bernard L. (eds.), Oxford University Press, 376-397.

Borghesi, S., Cainelli, G., Mazzanti, M., 2015. Linking emission trading to environmental innovation: evidence from the Italian manufacturing industry. Research Policy 44 (3), 669-683.

Borghesi, S., Montini, M., 2016. The best (and worst) of GHG emission trading systems: comparing the EU ETS with its followers. Frontiers in Energy Research 4, 27.

Borghesi, S., Montini, M., Barreca, A., 2016. The European Emission Trading System and Its Followers. Springer Briefs in Environmental Science.

Calel, R., Dechezlepretre, A., 2016. Environmental policy and directed technological change: evidence from the European carbon market. Review of Economics and Statistics 98 (1), 173191. 
Chang, T., Graff Zivin, J., Gross, T., Neidell, M., 2016. Particulate pollution and the productivity of pear packers. American Economic Journal: Economic Policy 8 (3), 141-69.

Ellerman, A. D., Buchner, B. K., 2008. Over-allocation or abatement? A preliminary analysis of the EU ETS based on the 2005-06 emissions data. Environmental and Resource Economics 41 (2), 267-287.

European Commission, 2015. Decision (EU) 2015/1814 of the European Parliament and of the Council of 6 October 2015 concerning the establishment and operation of a market stability reserve for the Union greenhouse gas emission trading scheme and amending Directive 2003/87/EC. Brussels, European Commission.

Fell, H., Burtraw, D., Morgenstern, R. D., Palmer, K. L., 2012. Soft and hard price collars in a cap-and-trade system: a comparative analysis. Journal of Environmental Economics and Management 64 (2), 183-198.

Graff Zivin, J., Neidell, M., 2012. The impact of pollution on worker productivity. American Economic Review 102 (7), 3652-73.

Graff Zivin, J., Neidell, M., 2013. Environment, health, and human capital. Journal of Economic Literature 51 (3), 689-730.

Grüll, G., Taschini, L., 2011. Cap-and-trade properties under different hybrid scheme designs. Journal of Environmental Economics and Management 61 (1), 107-118.

Hepburn, C., Neuhoff, K., Acworth, W., Burtraw, D., Jotzo, F., 2016. The economics of the EU ETS market stability reserve. Journal of Environmental Economics and Management (80), $1-5$.

Hofbauer, J., Sigmund, K., 1988. The Theory of Evolution and Dynamical Systems. Cambridge University Press.

Hoffmann, V. H., 2007. EU ETS and investment decisions: the case of the German electricity industry. European Management Journal 25 (6), 464-474.

International Carbon Action Partnership, 2017. Emissions Trading Worldwide: Status Report 2017. Berlin: ICAP.

International Carbon Action Partnership, 2018. Emissions Trading Worldwide: Status Report 2018. Berlin: ICAP.

Jung, C., Krutilla, K., Boyd, R., 1996. Incentives for advanced pollution abatement technology at the industry level: an evaluation of policy alternatives. Journal of Environmental Economics and Management 30, 95-111.

Kollenberg, S., Taschini, L., 2016. Emissions trading systems with cap adjustments. Journal of Environmental Economics and Management 80, 20-36.

Malueg, D., 1989. Emission credit trading and the incentive to adopt new pollution abatement technology. Journal of Environmental Economics and Management 18, 52-57.

Marcantonini, C., Teixido-Figueras, J., Verde, S., Labandeira, X., 2017. Low-carbon Innovation and Investment in the EU ETS. Issue 2017/22, Florence School of Regulation, European University Institute, Florence. 
Martin, R., Muûls, M., Wagner, U. J., 2016. The impact of the European Union Emissions Trading Scheme on regulated firms: what is the evidence after ten years? Review of Environmental Economics and Policy 10 (1), 129-148.

Milliman, S. R., Prince, R., 1989. Firm incentives to promote technological change in pollution control. Journal of Environmental Economics and Management 17, 247-265.

Moreno-Bromberg, S., Taschini, L., 2011. Pollution permits, strategic trading and dynamic technology adoption. CESifo Working Paper Series.

Newbery, D., Reiner, D., Ritz, R., 2018. When is a carbon price floor desirable? EPRG Working Paper No.1816 and Cambridge Working Paper in Economics No., 1833. Energy Policy Research Group, Cambridge UK.

Perino, G., Willner, M., 2016. Procrastinating reform: the impact of the market stability reserve on the EU ETS. Journal of Environmental Economics and Management 80, 37-52.

Requate, T., 2005. Dynamic incentives by environmental policy instruments - a survey. Ecological Economics 54, 175-195.

Rogge, K. S., Schneider, M., Hoffmann, V. H., 2011. The innovation impact of the EU Emission Trading System-Findings of company case studies in the German power sector. Ecological Economics 70 (3), 513-523.

Unold, W., Requate, T., 2001. Pollution control by options trading. Economics Letters 73 (3), 353-358.

Weibull, J. W., 1995. Evolutionary Game Theory. MIT Press.

Wood, P. J., Jotzo, F., 2011. Price floors for emissions trading. Energy Policy 39 (3), 1746-1753.

World Bank, Ecofys and Vivid Economics, 2017. State and Trends of Carbon Pricing 2017 (November), by World Bank, Washington, DC. 